\title{
Management protocol of hospitalized patients with COVID-19 in Babcock University Teaching Hospital, llishan-Remo, Ogun State, Nigeria
}

\author{
Ogunkoya $\mathrm{JO}^{1,2}$, Idowu $\mathrm{A}^{1,2}$, Oyedele $\mathrm{T}^{1,3}$, Elikwu $\mathrm{CJ}^{1.4}$, Ladele $\mathrm{A}^{1,5}$, Tuta $\mathrm{K}^{1,4}$, Bamidele \\ $\mathrm{EF}^{1,6}$
}

${ }^{1}$ Benjamin Carson Senior College of Health and Medical Sciences, Babcock University, Ilishan Remo, Ogun State, Nigeria.

${ }^{2}$ Department of Medicine, Babcock University Teaching Hospital, llishan Remo, Ogun State, Nigeria.

${ }^{3}$ Department of Surgery, Babcock University Teaching Hospital, Ilishan Remo, Ogun State, Nigeria.

${ }^{4}$ Department of Medical Microbiology, Babcock University Teaching Hospital, Ilishan Remo, Ogun State, Nigeria.

${ }^{5}$ Department of Family Medicine, Babcock University Teaching Hospital, llishan Remo, Ogun State, Nigeria. ${ }^{6}$ Department of Community Medicine, Babcock University Teaching Hospital, Ilishan Remo, Ogun State, Nigeria.

Submitted: $26^{\text {th }}$ March 2021

Accepted: $28^{\text {th }}$ April 2021

Published: $30^{\text {th }}$ June 2021

\begin{abstract}
Coronavirus infection became a global pandemic in March 2020. The number of hospitalized cases in Nigeria and Ogun State has been on a steady increase with a concomitant rise in Mortality. This necessitates a coordinated and a more systemic approach in the management of this deadly disease.

As a result of the potential effects of the disease on the socio-economic development of Ogun State, the state government granted Babcock University Teaching Hospital, Ilishan-Remo the permission to diagnose, admit and manage cases in line with Nigeria Centre for Disease Control (NCDC)/World Health Organization (WHO) guidelines. This led to the establishment of a molecular laboratory and a COVID-19 task force to oversee the treatment of confirmed cases of COVID-19 disease.

This protocol is developed to serve as a template for the diagnosis, admission, treatment of cases of COVID-19 diseases presenting for care in the hospital and to prevent the spread of the disease among healthcare workers within the hospital environment.
\end{abstract}

Keywords: Ageusia, Coronavirus disease, COVID-19, Paucisymptomatic, Remdesivir

\section{Introduction}

COVID-19 pandemic is caused by a severe respiratory syndrome coronavirus 2 (SARS COV2). It was first identified in Wuhan province, China in November 2019. This disease rapidly developed into a global pandemic by March 2020 resulting in over 122.2 million infections and more than 2.7 million deaths worldwide as of the middle of March 2021 (1).

The index case in Nigeria was publicized on the $27^{\text {th }}$ of February 2020. He was an Italian citizen who tested positive for the virus in Lagos a day before (2). On the $9^{\text {th }}$ of March 2020, a second 
case of the infection was reported in Ewekoro, Ogun State. He was a Nigerian who had contact with the Italian citizen (2). By March $31^{\text {st, }} 2020$, 135 cases had been confirmed $(2,3,4)$. The suspected cases being traced in Nigeria rose to 6,000 within 10 days of the first confirmed case. As of $19^{\text {th }}$ March 2021, Nigeria had recorded over 161,409 cases with a mortality of over 2027 (2). In Ogun State, Southwest Nigeria, the number of cases and mortality as of $19^{\text {th }}$ March 2021 stood at 4,591 and 49 deaths respectively (2).

The incubation period is around 2-14 days from the initial infection. The most frequently experienced symptoms include fever, dry cough, dyspnoea, anosmia, ageusia, and fatigue $(5,6)$. However, individuals with no symptoms are among the most active spreader of the virus. Among symptomatic individuals, most disease transmission occurs 3-5 days before the onset of symptoms (7). The spectrum of disease is broad and ranges from true asymptomatic or paucisymptomatic infection to fatal acute respiratory distress syndrome $(8,9)$. The mortality rate of COVID-19 is still being debated but seems to be lower than Middle East Respiratory Syndrome and Severe Acute Respiratory Syndrome The mortality rate among hospitalized patients ranges from $5-25 \%(10,11$, 12).

Studies have shown that COVID-19 is a biphasic illness with distinct phases $(13,14)$. The first phase of infection starts with fever, cough, and anosmia. This phase is associated with very high viral loads with the peak occurring within the first seven days of illness (14). The second phase which does not occur in all patients is characterized by a dysfunctional host inflammatory response which leads to the development of lung inflammation and subsequently the final phase of lung injury follows $(15,16)$. The inflammatory response in moderate and severe COVID-19 has been variously described as a pro-inflammatory cytokine storm or a manifestation of profound immunosuppression $(17,18)$. It is however very clear that the inflammatory changes lead to an increase in inflammatory markers such as IL-6, $\mathrm{IL}-8, \quad \mathrm{IL}-1 \beta$ and activation of the coagulation pathways (19).

The number of hospitalized cases in Nigeria and Ogun State has been on the increase towards the latter part of the year 2020 with the health care facilities of the state being overwhelmed. This led to the Government of Ogun State giving written permission to Babcock University Teaching Hospital, a private tertiary health institution in
Nigeria, to admit and manage confirmed cases of COVID-19 disease.

\section{Aim and purpose of COVID-19 protocol}

To provide quality care to all patients with COVID19 disease, especially the citizens of Ogun State, Nigeria.

This document outlines the process by which COVID-19 cases are evaluated and managed at Babcock University Teaching Hospital via the establishment of a COVID-19 task force (CTF).

\section{THE need for COVID-19 Task Force (CTF)}

The hospital authority identified the COVID-19 task force as the linkage between the hospital, the local and state authorities. The following were put in place by the hospital authority and CTF:

i. A well-equipped facility that can accommodate at least 10 patients at a time, including 2 spaces for very important personalities (VIPs).

ii. An individual patient is placed in a separate room with adequate furniture and space.

iii. 24-hours electricity supply with a functioning Television/cable network is available.

iv. Adequate toilet facilities are available at the facility.

v. Adequate ventilation assisted by the use of electric fans and air conditioning systems is available at the facility.

vi. The Hub and Spoke model is employed to provide services to the patients. This is a centralized system of care in which all items are sent to the hub (caregivers) for onward distribution to the patients.

vii. Transmission-based precautions are practiced by all health care workers and patients at all times. Physical distancing is practiced by healthcare workers and patients.

\section{Administrative control of CTF}

The administrative control over the activities of the CTF was assigned to the office of the Deputy Director of Clinical Services of Babcock University Teaching Hospital, Ilishan-Remo, Ogun State.

Duties and responsibilities

i. The Deputy Director of Clinical Services utilizes the services of a required number of medical staff, paramedical staff, and public health staff for the critical functional components of the CTF without affecting the smooth running of the hospital.

ii. The Deputy Director of Clinical Services works with four (4) nodal officers who are 
responsible for imparting capacity building to different categories of staff and the day-to-day running of the isolation wards.

iii. The nodal officers are Consultants in Respiratory Medicine, Infectious Diseases/ Clinical Microbiology, Family Medicine, and Community Medicine.

iv. The nodal officers are on a weekly roster and work in conjunction with other consultants, junior and senior residents to provide 24hours coverage of the COVID-19 Isolation/Treatment Unit.

v. Comorbidities are appropriately managed and proper clinical documentation is ensured.

vi. Three nurses are posted per shift for a 12hour for a week and they join doctors on rounds twice a day.

vii. Other staff members such as oxygen technicians, cleaners, and porters are available.

\section{Triage and registration}

i. Triage is done in an open space located outside the Accident and Emergency Department of the hospital with adequate lighting and ventilation.

ii. An office table and a chair are provided for the nurse on duty. Two chairs are also placed on the opposite side for the patients.

iii. The triage area utilizes the following: screening questionnaire, documentation papers, personal protective equipment (PPE), hand hygiene equipment, infrared thermometer, blood pressure (BP) measurement apparatus, pulse oximeter, stethoscope, waste bins, and access to cleaning/disinfection.

iv. Signage in the local language (Yoruba) for patients with specific symptoms to alert healthcare workers.

v. At least one (1) wheelchair and a stretcher trolley are available for use.

vi. The information taken by the triage nurse includes name, age, address and mobile number of the patient, name and mobile number of contact person, presenting complaints, history of presenting complaint, history of travel to localities with a high infection rate/contact with COVID-19 positive case, presence of co-morbid conditions like diabetes, hypertension, chronic obstructive pulmonary disease (COPD), cancer, renal disease, mental illness, any other chronic illnesses with treatment details.

vii. Based on the medical history and clinical parameters, triaging was done into three categories of suspected cases (mild symptomatic, moderate symptomatic with or without co-morbidity, and severe symptomatic with or without co-morbidity) $(20,21)$.

viii.Mild symptomatic cases are tested with Reverse Transcriptase Polymerase Chain Reaction (RT-PCR) test and advised to selfisolate at home for 10-14 days. Contacts of positive patients are also encouraged to be tested and/or self-isolated for 10-14 days.

ix. The moderate to severe cases are admitted in isolation wards and treated with recommended medications and comorbidities are also adequately managed. They are subsequently discharged after a negative RTPCR test scheduled for follow-up in outpatient clinics.

\section{Patient responsibilities}

i. To follow the rules and regulations of the Centre.

ii. To follow the Instructions of CTF staff.

iii. Wear face mask properly and keep physical distancing.

iv. Practice infection control measures such as hand washing, maintain healthy habits, and avoid spitting in any place other than a washbasin.

v. Take medication as prescribed and administered by the doctor(s) and nurse(s).

\section{Criteria for admission}

i. The individual must have been adequately triaged, tested with a positive RT-PCR result, and classified as a case of moderate to severe COVID-19 disease.

ii. The individual must have paid the required fee for admission. If unable to pay the admission fee, the patient is transferred to Ogun State Government free treatment centers for further care.

iii. The patients and relatives must all agree to abide by the rules and regulations of the wards.

\section{COVID-19 sample collection}

i. A dedicated area for swab sample oropharyngeal and nasopharyngeal (OP and NP) collection and a walk-in sample (OP and NP) collection point is provided.

ii. A room with good ventilation and lighting provided for donning and doffing of PPE.

iii. The location for walk-in sample collection is at the farthest end of the ward with separate entry from outside the ward and inside. 
iv. Wash area with elbow tap, soap dispenser, and sanitizer are available.

v. Paper towels are provided to staff and patients to dry washed hands.

vi. Two chairs, one each for the doctor and walk-in patients, and a side table with an adjustable stand lamp.

vii. Disposable tongue depressors are available for use.

viii. Samples collected are immediately sent to the molecular laboratory and processed within 12 hours.

\section{Infection Prevention and Control, donning and duffing area}

Hospital infection prevention and control are of prime importance and are observed at all times. Both standard and transmission-based precautions are observed. Adequate PPE for each caregiver is provided at all times.

i. Separate room for Donning and Doffing close to the collection point available and adequate.

ii. Washbasins with elbow tap, soap, water, and hand sanitizers are available.

\section{Single room facility for patients}

i. The rooms for each patient are clean, well ventilated with adequate lighting.

ii. Each room has a toilet attached.

iii. A comfortable bed with a mattress and pillow is provided.

iv. A table with a chair is provided.

v. Separate feeding utensils and flask are provided for each room.

\section{Pharmacy services}

All dedicated drugs are kept in the hospital pharmacy for easy access and collection for use of patients.

\section{Laboratory services}

i. The main laboratories of the hospital serve the COVID-19 patients as well, with strict Infection Prevention and Control measures.

ii. Samples are collected by the attending doctors.

iii. Transportation of samples and issue of reports are incorporated into the general administrative system of the hospital.

\section{Laundry services}

The hospital provides a dedicated laundry for linen and bed sheets used on the ward.

\section{Dietary services}

I. Family members provided daily dietary needs of the patient on admission on a timely basis.

II. Clean water in a dispenser is provided for each patient.

\section{Psychosocial support}

The hospital provides psychosocial support to the patients and family members during admission and after discharge through the psychiatric unit of the hospital to prevent immediate and long-term mental health disorders.

\section{Useful drugs in the management of COVID-19 positive patients}

I. Nonsteroidal anti-inflammatory drugs (NSAIDs) and oral acetaminophen: Oral acetaminophen is the preferred antipyretic agent. If other NSAIDs (e.g. Ibuprofen) are needed, it is better to use the lowest effective dose. The available data in support of the use of NSAIDs in the setting of COVID-19 is minimal (22).

II. Glucocorticoids: Administered as an inhaled medication through a nebulizer. WHO recommends that systemic glucocorticoids have no role in the management of COVID-19 patients unless there are other indications (e.g. COPD and critically ill patients). Treatment with corticosteroids for patients with COVID-19 should be administered only to patients requiring oxygen, non-invasive ventilation (NIV), or invasive mechanical ventilation (INV) (11).

III. Managing chronic conditions with ACEs/ARBs: Patients receiving angiotensin-converting enzyme inhibitors/angiotensin receptor blockers (ACEI/ ARBs) should continue treatment with these agents if there is no other reason for discontinuation [e.g. Hypotension, acute kidney injury (AKI)]. The speculation that the patients receiving these agents may be at high risk for adverse outcomes, has not been supported by findings from observational studies. Conversely, there has been no evidence to support the speculation that ACEIs/ARBs have potential protective effects.

IV. Statins: Statins should be continued in hospitalized COVID-19 patients who were previously on the medication. Although clinicians may be concerned about hepatotoxicity from statins, particularly since transaminase elevations are common in 
COVID-19; available evidence indicates that liver injury from statins is uncommon.

V. Antibiotics: Empirical treatment with antibiotics (e.g. Azithromycin) for Secondary bacteria pneumonia infection is reasonable in patients with documented COVID 19 if there is evidence to support the diagnosis.

VI. Anticoagulation: Prevention of thromboembolism via both pharmacological and non-pharmacological intervention among hospitalized patients should be used in the care of hospitalized COVID-19 patients [e.g. use of TED stockings, early ambulation, and Low molecular weight heparin (LMWH)].

VII. Remdesivir: it is an inhibitor of the viral RNA-dependent RNA polymerase. It might be used if available. It has proven effective in-vitro against SARS-CoV-1, MERS-CoV, and SARS-CoV-2 (19). A reduction in time to recovery and length of hospital stay was demonstrated for Remdesivir in one trial (ACTT1) (19) but no clinical benefits were demonstrated in the large SOLIDARITY trial which found no evidence of a mortality benefit $(23,24)$.

VIII. Oxygen administration: High flow oxygen via a nasal catheter (HFNC) or non-invasive continuous positive airway pressure (CPAP) delivered through either a helmet or a face mask administered to patients with COVID19 and hypoxaemic acute respiratory failure without an immediate indication for invasive mechanical ventilation.

IX. Mild COVID-19 cases: will be managed at home if no comorbidity and age are below 60 years. Such patients will be given oral Ivermectin $12 \mathrm{mg}$ daily for 3 days, Dexamethasone $6 \mathrm{mg}$ daily for 10 days, Vitamin C $1 \mathrm{~g}$ daily for 14 days, Vitamin D $250 \mathrm{IU}$ daily for 14 days, and Zinc $100 \mathrm{mg}$ daily for 14 days.

$X$. Moderate to severe cases: will be managed in the hospital. Such patients will be given oral Azithromycin $250 \mathrm{mg}$ daily for 3 days, subcutaneous injection Clexane 40IU daily, parenteral/oral antibiotics for lower respiratory tract infection as indicated, and high flow oxygen as required.

\section{Discharge and follow-up}

i. Patients are discharged home after testing negative to COVID-19 10-14 days after admission and advised to keep all the necessary preventive measures of COVID-19. ii. Patients are also advised to be vaccinated for COVID-19 when the vaccine is available.

iii. An appointment for follow-up is given for two weeks for further review in the infectious disease clinic to continue to detect and manage long-term sequelae of the COVID-19 disease, such as chronic fatigue, tiredness, and body pain.
Abbreviations:
ACEl:
Angiotensin-converting enzyme
AKI:
Acute kidney injury
ARBs:
Angiotensin receptor blockers
INV:
Invasive ventilation
LMWH:
Low molecular weight heparin
NCDC:
Nigeria Centre for Disease
Control
NIV:
NSAID:
Non-Invasive ventilation
agent
OP and NP: Oro-pharyngeal and
Nasopharyngeal
WHO: $\quad$ World Health Organization
PPE: $\quad$ Personal protective equipment

\section{Declarations}

Ethical approval

Ethical approval and consent to participate not applicable.

\section{Consent for Publication}

The authors hereby give consent for the publication of our work under the creative commons CC Attribution-Non-commercial 4.0 license.

\section{Conflict of Interest}

The authors have no conflict of interest to declare.

\section{Funding}

The authors received no funding for this work.

\section{Authors" Contributions}

JOO was responsible for the concept, literature search, drafting, and review of the manuscript. Al was responsible for the concept, literature search, drafting, and review of the manuscript. TO was responsible for the concept, literature search, drafting, and review of the manuscript. CJE was responsible for the literature search, drafting, and review of the manuscript. AL was responsible for the literature search, drafting, and review of the manuscript. KT was responsible for the literature search, drafting, and review of the 
manuscript. EFB was responsible for the literature search, drafting, and review of the manuscript.

\section{Acknowledgment}

We acknowledge Dr. Olumide Abiodun for his assistance during the production of this work.

\section{References}

1. Worldometer, Coronavirus (Covid 19) update (live), 2021 \{cited2021, March 14\}. https://www.worldometers.info/coronaviru $\underline{s}$

2. Nigerian Centre for Disease Control. First Case of Corona Virus Disease confirmed in Nigeria. April 1 1st, 2020. https://ncdc.gov.ng/diseases/sitreps/?cat= 14\&name=An\%20update $\% 200 f \% 20$ COVI D-19\%200outbreak\%20in\%20Nigeria

3. Ajisegiri W, Odusanya O, Joshi R. COVID19 outbreak situation in Nigeria and the need for effective engagement of community health workers for epidemic response. Global Biosecurity. 2020 Jun 22;1(4). https://doi.org/10.31646/gbio.69

4. Shoring up Covid-19 prevention in Nigeria's border states. WHO Africa. https://www.afro.who.int/sites//default/files 12020-10/WHO

5. Nishiura H, Linton NM, Akhmetzhanov AR. Serial interval of novel coronavirus (COVID-19) infections. International Journal of infectious diseases. 2020 Apr 1;93:284-6.

https://doi.org/10.1016/j.jijid.2020.02.060

6. Guan WJ, Ni ZY, Hu Y, Liang WH, Ou CQ, He JX, Liu L, Shan H, Lei CL, Hui DS, Du B. Clinical characteristics of coronavirus disease 2019 in China. New England journal of medicine. 2020 Apr 30;382(18):1708-20.

7. Bai Y, Yao L, Wei T, Tian F, Jin DY, Chen L, Wang M. Presumed asymptomatic carrier transmission of COVID-19. Jama. 2020 Apr 14;323(14):1406-7. https://doi.org/10.1001/jama.2020.2565

8. Wu G, Yang P, Xie Y, Woodruff HC, Rao X, Guiot J, Frix AN, Louis R, Moutschen M, $\mathrm{Li} \mathrm{J}, \mathrm{Li} \mathrm{J}$. Development of a clinical decision support system for severity risk prediction and triage of COVID-19 patients at hospital admission: an international multicentre study. European Respiratory Journal. 2020 Aug 1;56(2). https://doi.org/10.1183/13993003.01104$\underline{2020}$
9. Acosta MA, Singer BD. Pathogenesis of COVID-19-induced ARDS: implications for an ageing population. European Respiratory Journal. 2020 Sep 1;56(3). https://doi.org/10.1183/13993003.02049$\underline{2020}$

10. Liang WH, Guan WJ, Li CC, Li YM, Liang HR, Zhao $Y$, Liu XQ, Sang L, Chen RC, Tang CL, Wang T. Clinical characteristics and outcomes of hospitalised patients with COVID-19 treated in Hubei (epicentre) and outside Hubei (non-epicenter): a nationwide analysis of China. European Respiratory Journal. 2020 Jun 1;55(6). https://doi.org/10.1183/13993003.005622020

11.Zhou F, Yu T, Du R, Fan G, Liu Y, Liu Z, Xiang J, Wang Y, Song B, Gu X, Guan L. Clinical course and risk factors for mortality of adult inpatients with COVID-19 in Wuhan, China: a retrospective cohort study. The lancet. 2020 Mar 28;395(10229):1054-62.

https://doi.org/10.1016/s01406736(20)30566-3

12. Chalmers JD, Crichton ML, Goeminne PC, Cao B, Humbert $M$, Shteinberg $M$, Antoniou KM, Ulrik CS, Parks H, Wang C, Vandendriessche T. Management of hospitalised adults with coronavirus disease 2019 (COVID-19): A European Respiratory Society living guideline. European respiratory journal. 2021 Apr $1 ; 57(4)$.

https://doi.org/10.1183/13993003.000482021

13. Siddiqi HK, Mehra MR. COVID-19 illness in native and immunosuppressed states: a clinical-therapeutic staging proposal. The Journal of Heart and Lung Transplantation. 2020 May;39(5):405 https://doi.org/10.1016/j.healun.2020.03.0 12

14. Cevik M, Tate M, Lloyd O, Maraolo AE, Schafers J, Ho A. SARS-CoV-2, SARSCoV, and MERS-CoV viral load dynamics, duration of viral shedding, and infectiousness: a systematic review and meta-analysis. The Lancet Microbe. 2020 Nov 19. https://doi.org/10.1016/s2666$\underline{5247(20) 30172-5}$

15. Mann ER, Menon M, Knight SB, Konkel JE, Jagger C, Shaw TN, Krishnan S, Rattray M, Ustianowski A, Bakerly ND, Dark P. Longitudinal immune profiling reveals key myeloid signatures associated 
with COVID-19. Science immunology. 2020 Sep 17;5(51). https://doi.org/10.1126/sciimmunol.abd61 97

16. Laing AG, Lorenc A, Del Barrio ID, Das A, Fish M, Monin L, Muñoz-Ruiz M, McKenzie DR, Hayday TS, Francos-Quijorna I, Kamdar S. A dynamic COVID-19 immune signature includes associations with poor prognosis. Nature medicine. 2020 Oct;26(10):1623-35.

https://doi.org/10.1038/s41591-020-1038$\underline{6}$

17. Remy KE, Mazer M, Striker DA, Ellebedy $\mathrm{AH}$, Walton $\mathrm{AH}$, Unsinger J, Blood TM, Mudd PA, Daehan JY, Mannion DA, Osborne DF. Severe immunosuppression and not a cytokine storm characterizes COVID-19 infections. JCI insight. 2020 Sep $3 ; 5(17)$. https://doi.org/10.1172/jci.insight.140329

18. Chen LY, Hoiland RL, Stukas S, Wellington CL, Sekhon MS. Confronting the controversy: interleukin-6 and the COVID-19 cytokine storm syndrome. https://doi.org/10.1183/13993003.03006$\underline{2020}$

19. Galani IE, Rovina N, Lampropoulou V, Triantafyllia V, Manioudaki M, Pavlos E, Koukaki E, Fragkou PC, Panou V, Rapti V, Koltsida $O$. Untuned antiviral immunity in COVID-19 revealed by temporal type I/III interferon patterns and flu comparison. Nature immunology. 2021 Jan;22(1):3240. https://doi.org/10.1101/2020.08.21.20179 $\underline{291}$

20.Nigeria Center for Disease Control (NCDC). National Guidelines for clinical Management of Covid-19 Version 1: 2020; 1-39.

https://ncdc.gov.ng/themes/common/docs /protocols/177 1584210847.pdf

21. World Health Organization. Report of the WHO- China Joint Mission on Coronavirus Disease 2019. April 2020. https//doi.org/10.3410/f.737509210.79357 2.110

22. Howard Harry. You can take Ibuprofen to treat coronavirus, Government Panel experts concludes. Dailymail. April 14, 2020.

https://www.dailymail.co.uk/health/article8218663/You-ibruprofen-treatcoronavirus-Government-panel-expertsconcludes.html

23. Beigel JH, Tomashek KM, Dodd LE, Mehta AK, Zingman BS, Kalil AC et al. Remdesivir for the Treatment of Covid19 - Final Report. The New England Journal of Medicine. 2020 Nov 5;383(19):1813-

1826. https://doi.org/10.1056/NEJMoa200 7764

24. WHO Solidarity Trial Consortium. Repurposed antiviral drugs for COVID19-interim WHO SOLIDARITY trial results. New England journal of medicine. 2021 Feb 11;384(6):497-511. https://doi.org/10.1056/nejmoa2023184 